\title{
Low Temperature Phase Separation in Nanowires
}

\author{
Sheng Yun $\mathrm{Wu}$ \\ Department of Physics, National Dong Hwa University \\ Taiwan, R. O. C.
}

\section{Introduction}

The ways to develop one-dimensional (1D) nanostructures, such as nanowires, nanorods, nanobelts and nanotubes, are being studied intensively, due to their unique applications in mesoscopic physics and nanoscale electronic devices [1-3]. Structural phase transition between the wurtzite (WZ) and zinc-blend (ZB) GaN induced by the deposition conditions [4], temperature-mediated phase selection during the growth of $\mathrm{GaN}$ [5], and substrate control [6] by the crystallographic alignment of $\mathrm{GaN}$ have all been observed. It is known that $\mathrm{x}$-ray scattering technique plays an important role in investigating the lattice excitations and structural transformation associated with thermal strain in 1D nanowires [7]. For example, Dahara and co-workers [8] reported a phase transformation from hexagonal to cubic in $\mathrm{Ga}^{+}$implaned GaN nanowires (GaNWs). The SC16 phase of GaAs appears at high pressure can be transformed to the hexagonal $\mathrm{WZ}$ phase by reducing the pressure to the ambient one. WZ GaAs is stable in resisting a transformation to the ZB phase at temperatures up to $473 \mathrm{~K}$ at ambient pressure [9]. Currently, most of the studies on the crystalline structure of GaNWs are focused on the stable hexagonal $\alpha-\mathrm{GaN}$ and metal-stable cubic $\beta-G a N$. In this work, we study the crystalline structure of GaNWs by using in situ lowtemperature $\mathrm{x}$-ray diffraction and Rietveld analysis [10]. Our findings show that the ZB phase starts to develop below $260 \mathrm{~K}$. A finite size model wherein the random phase distribution is utilized to describe the development of short range atomic ordering. The phase separation was found to be reversible upon temperature cycling, and occurred through the exchange and interaction of the characteristic size of the ordered domain of the GaN nanowires.

\section{Important}

In situ low temperature $\mathrm{x}$-ray diffraction was employed to investigate the phase separation of $\mathrm{GaN}$ nanowires. Observations showed that a distinct phase separation developed below $260 \mathrm{~K}$, the Zinc-Blend phase, which was related to short range ordering. Surprisingly, the correlation lengths of the Zinc-Blend phase reached their maximum at $140 \mathrm{~K}$ but correlation length was still revealed at around $23 \mathrm{~nm}$. Our results may be understood using the short range correlation model, and support the conclusion that the phase separation was reversible and occurred through the interaction of the characteristic size of the ordered domain of the GaN nanowires. 


\section{Experimental details}

$\mathrm{GaN}$ is a direct wide band-gap semiconductor at room temperature. It is a prominent candidate for optoelectronic devices at blue and near ultra-violet wavelengths [11-14]. In addition, it exhibits high thermal conductivity and little radiation damage, suitable for high temperature and high power microelectronic devices[15]. GaN nanowires have been synthesized by several groups using different methods[16-22]. The randomly oriented GaNWs used in this study were synthesized by a low pressure thermal chemical vapor deposition (LPTCVD) technique. The samples were grown at $950 \circ \mathrm{C}$ on Si [001] substrates precoated with a $5 \mathrm{~nm}$ Au catalyst layer by an E-Gun evaporator. Molten gallium was used as the source material and $\mathrm{NH}_{3}(30 \mathrm{sccm})$ as the reactant gas in a horizontal tubular furnace. Details of the growth process may be found elsewhere [23]. A low temperature in situ X-ray diffractometer (Scintag 2000) was utilized to investigate the crystalline structure of the GaNWs produced at various temperatures. The specimens were mounted on backgroundfree sample holders, which were then attached to a cold-head placed in a high vacuum ( < 10-6 Torr) environment. The chamber was equipped with a beryllium hemisphere, and evacuated to reduce air scattering and absorption of the $x$-ray. No obvious differences were found in the x-ray diffraction patterns taken on different portions of the sample.

\section{Results and discussion}

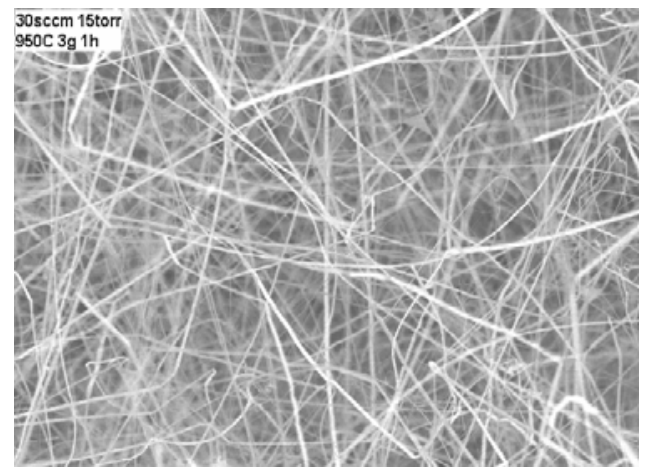

Fig. 1. SEM micrograph of GaNWs homogeneously grown on the substrate.

\subsection{SEM results}

The morphology of sample was characterized by a field emission scanning electron microscope (FE-SEM, JEOL JSM-6500F) equipped with an energy dispersive $x$-ray spectroscope (EDS, Oxford Instrument INCA x-sight 7557). Atomic-resolution transmission electron microscopic (TEM) analysis and high-resolution transmission electron microscopy (HRTEM) images were taken with the CCD-camera of an electron microscope (JEOL JEM2100) at $200 \mathrm{kV}$. Analysis software (Digital Micrograph) was employed to digitalize and analyze the obtained images. Figure 1 displays a portion of the SEM image showing the morphology of the GaNWs. The diameters of the GaNWs assembly ranged from 20 to 50 $\mathrm{nm}$, with a length of several tens of microns. The diameter distribution of the GaNWs assembly, as shown in the Fig. 2, is quite asymmetric and can be described using a lognormal distribution function (solid line). The log-normal distribution is defined as follows: 
$f(d)=\frac{1}{\sqrt{2 \pi} d \sigma} \exp \left(-\frac{(\ln d-\ln \bar{d})^{2}}{2 \sigma^{2}}\right)$, where $\bar{d}$ is the mean value and $\sigma$ is the standard deviation of the function. The mean diameter obtained from the fit is $<d>=40(3) \mathrm{nm}$. The small standard deviation $(\sigma<0.5)$ of the function indicates that the distribution is confined to a limited range. The broadening of the width of the distribution profile is due to crystalline and nanoparticle aggregation effects.

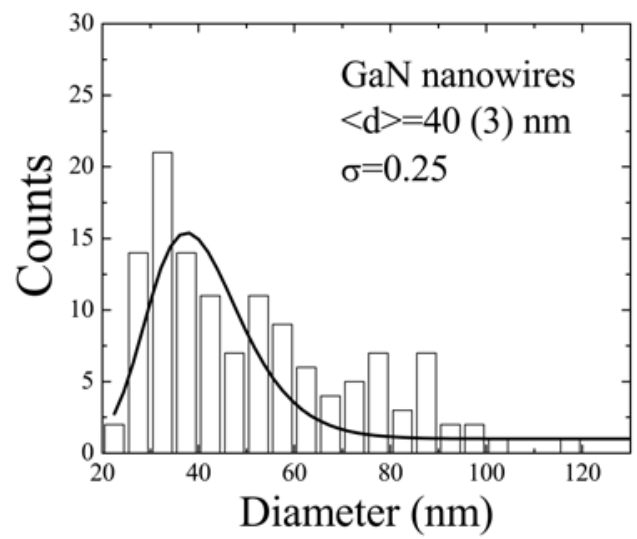

Fig. 2. The diameter distribution of the GaNWs obtained from SEM images.

\subsection{TEM and HRTEM results}

Figure 3 shows the TEM morphology of a typical nanowire. TEM image reveals that most of the nanowires are straight, and the diameter along the growth direction is uniform, with a mean diameter of $40(3) \mathrm{nm}$. Figure 4 shows the selected area electron diffraction (SAED) pattern taken on a region close to the surface of a single nanowire. It clearly reveals a single crystalline nature for the sample studied. The Bragg spots correspond to the [001] reflection of the wurtzite structure of the GaNW. The pattern of the main spots can easily be seen as hexagonal cells with lattice parameters of $a=3.195 \AA$ and $c=5.193 \AA$, which indicates a predominantly polycrystalline hexagonal wurtzite $\mathrm{GaN}$, shown in Fig. 5. In wurtzite

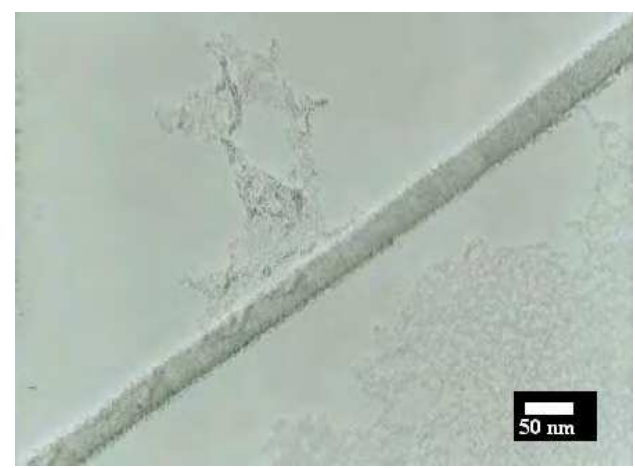

Fig. 3. TEM image of the GaNWs revealing a uniform diameter of $\sim 40 \mathrm{~nm}$. 


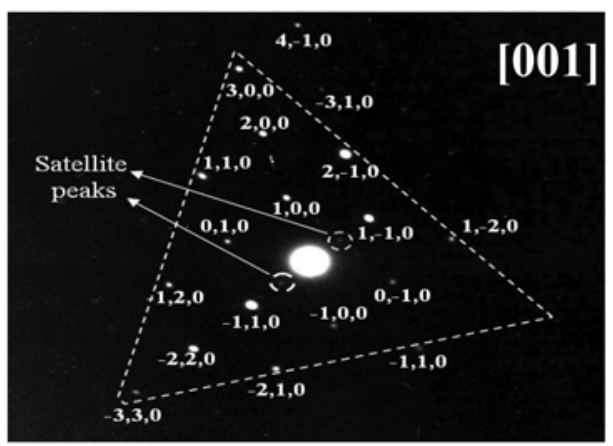

Fig. 4. SAED pattern of the GaNWs confirming the [001] growth direction.

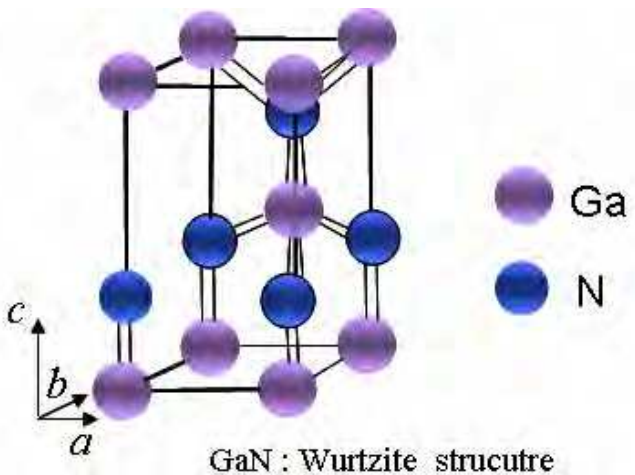

Fig. 5. Crystal structure of WZ-GaN.

structure of GaNWs, on the surface of [001], each Ga atom has three complete bonds to the underlying nitrogen atomic plane. Details of the description of crystal structure may be found with the earlier finding [24].

\subsection{X-ray diffraction}

X-ray diffraction patterns are known as the fingerprints of crystalline materials. They reveal details of the crystalline structure and their formation during synthesis, and even the crystalline phase transitions or separation at various temperatures. The $\mathrm{x}$-ray and Rietveld refined diffraction patterns of the GaNWs, taken at $320 \mathrm{~K}$ and $80 \mathrm{~K}$, are shown in Fig. 6 and 7 , respectively. Diffraction patterns were utilized to characterize the crystalline structure in the prepared samples. The diffraction peaks appeared to be much broader than the instrumental resolution, reflecting the nano-size effects. The analysis was performed using the program package of the General Structure Analysis System (GSAS) [25] following the Rietveld method [10]. Several models with different symmetries were assumed during the preliminary analysis. In our structural analysis we then pay special attention to searching for the possible symmetries that can describe the observed diffraction pattern well. All the structural and lattice parameters were allowed to vary simultaneously, and refining processes were carried out until $R_{\mathrm{p}}$, the weighted $R_{w p}$ factor, differed by less than one part in a thousand within two successive cycles. Figure 6 shows the diffraction pattern (black cross) 
taken at room temperature, where the solid curve (red curve) indicates the fitted pattern and the differences (blue curve) between the observed and the fitted patterns are plotted at the bottom of Fig. 6. The refined lattice parameters at $320 \mathrm{~K}$ are $a=b=3.195$ (2) $\AA$ and $c=5.193(1)$ $\AA$. This $c / a=1.625$ that we obtained for the $\mathrm{WZ}$ structure agrees very well with that obtained in a separated study [26], but is $\sim 0.5 \%$ smaller than the theoretically expected value [27] of 1.633. The reasons for this are not completely clear, but could be due to the nanowires are expected to grow in the $c$-direction that resulted in a smaller length-to-width ratio.

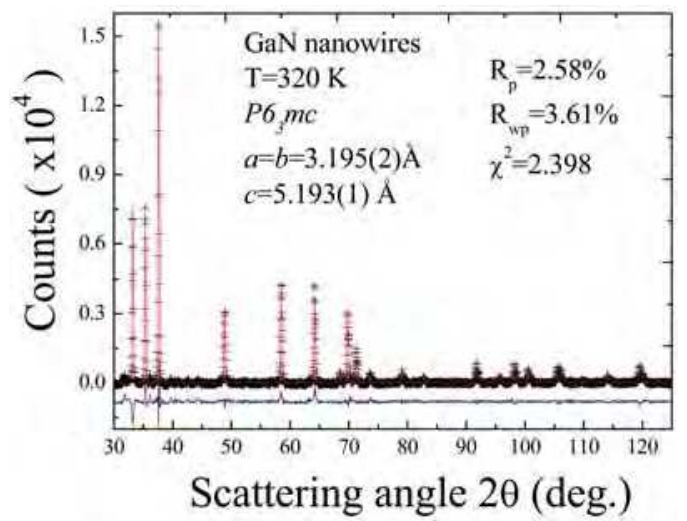

Fig. 6. The observed (crosses) and Rietveld refined (solid lines) x-ray diffraction patterns of GaNWs taken at $320 \mathrm{~K}$.

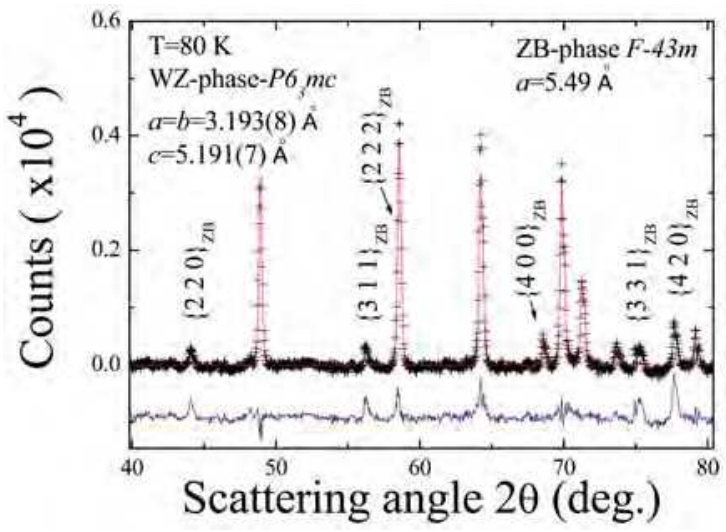

Fig. 7. The observed (crosses) and Rietveld refined (solid lines) x-ray diffraction patterns of GaNWs taken at $80 \mathrm{~K}$. A new set of diffraction peaks that is associated with the zinc-blend phase appears in the pattern taken at $80 \mathrm{~K}$.

A series of new peaks, at scattering angles of $44.08^{\circ}, 56.22^{\circ}, 58.2^{\circ} 68.2^{\circ}$, and $75.3^{\circ}$, becomes visible in the diffraction patterns taken at $80 \mathrm{~K}$, as can be seen in the Fig. 7. These peaks were not observed at $320 \mathrm{~K}$ and cannot be associated to the $\alpha-G a N W$. They, however, may be indexed as the $\{220\}_{\mathrm{ZB}},\{311\}_{\mathrm{ZB}},\{222\}_{\mathrm{ZB}},\{400\}_{\mathrm{ZB}},\{331\}_{\mathrm{ZB}}$, and $\{420\}_{\mathrm{ZB}}$ reflections of the ZB phase, shown in Fig.8. All these new peaks may be identified to belong a cubic $F-43 m$ GaN 
structure of lattice constant $a=5.49 \AA$. All the x-ray diffraction patterns taken on the sample holder, on the silicon substrate, and on the empty chamber reveal no such signals.

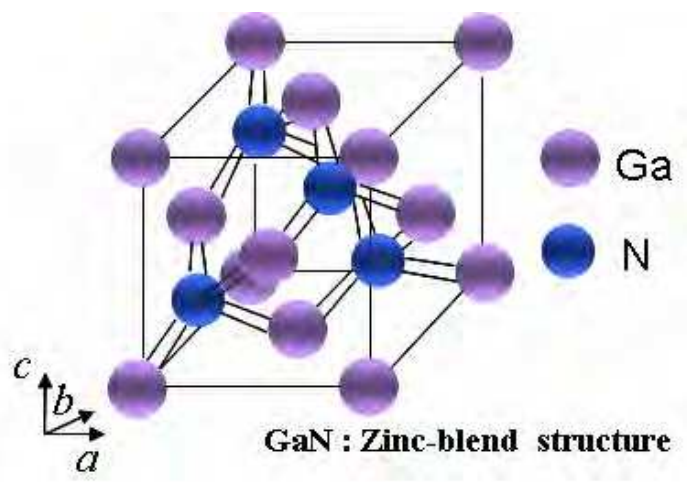

Fig. 8. Crystal structure of ZB-GaNWs.

\subsection{In situ low temperature X-ray diffraction}

Figure 9 shows the temperature dependency of the in situ x-ray diffraction patterns, where the color bars represent the diffraction intensity. The $\{112\}_{\mathrm{WZ}},\{201\}_{\mathrm{WZ}},\{004\}_{\mathrm{WZ}}$, and $\{202\}_{\mathrm{WZ}}$ reflections are clearly revealed at high temperatures, while the $\{331\}_{Z B}$ and $\{420\}_{Z B}$ reflections develop below $260 \mathrm{~K}$. No obvious changes in the width of the diffraction peaks that belong to the WZ-phase may be identified in the temperature regime studied, as can be seen in the Fig. 10 where FWHM represents the full width at half maximum of the diffraction peak. Figure 11 and 12 show the temperature dependency of the integrated intensity and the FWHM of the $\{420\}_{Z B}$ reflection, respectively. Below $260 \mathrm{~K}$, the integrated intensity of the

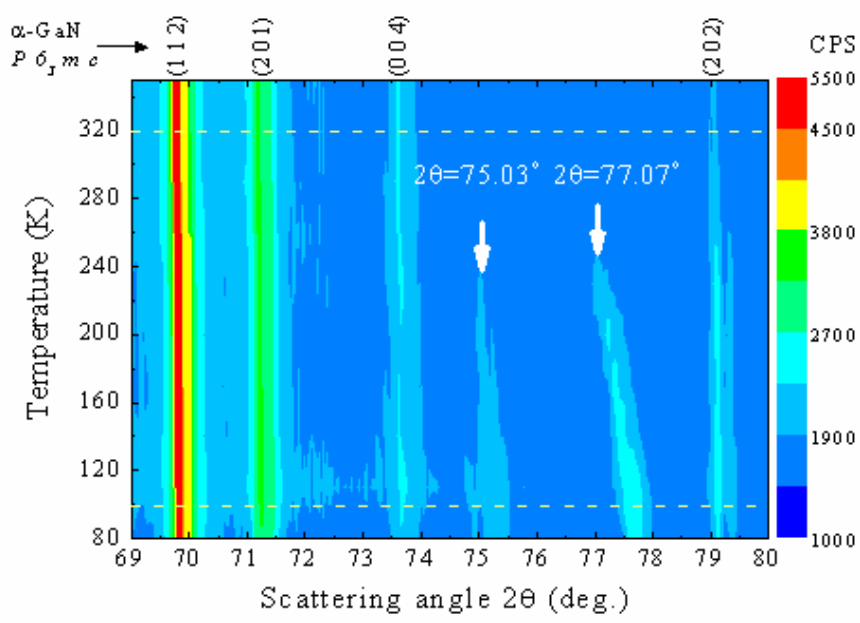

Fig. 9. Plots of the temperature dependence of the in situ low-temperature x-ray diffraction patterns. 


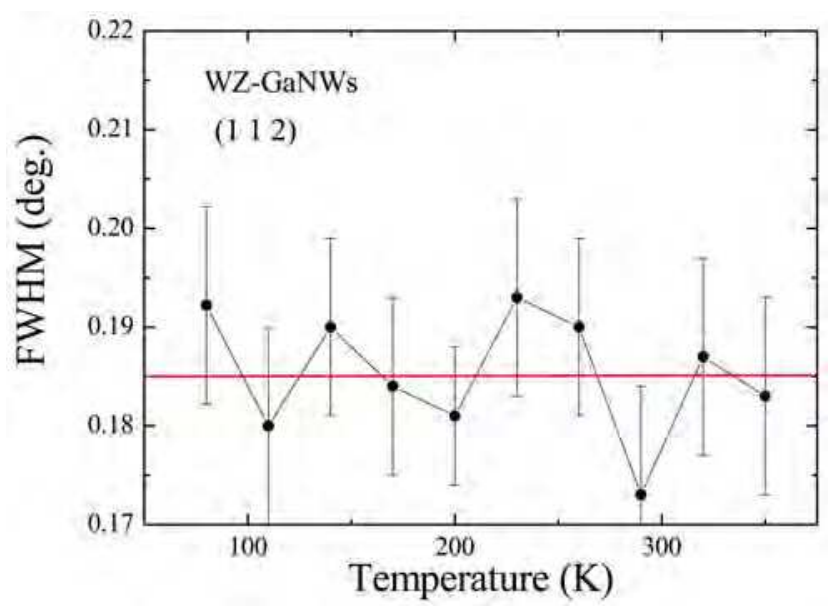

Fig. 10. The FWHM of the $\{112\}_{\text {WZ }}$ reflection taken at various temperatures, revealing a monotonic change of the FWHM is related to the fluctuation in temperature or to the fit of the error bar.

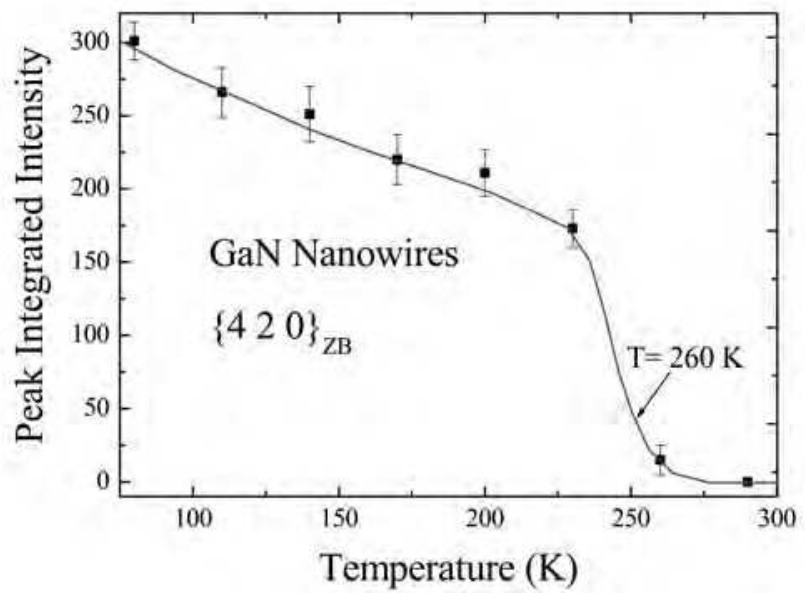

Fig. 11. Temperature dependence of the integrated intensity of the $\{420\}_{Z B}$ reflection, where the solid curve is guide to the eye only. A distinct structural transformation may be clearly seen to occur at around $260 \mathrm{~K}$.

$\{420\}_{Z B}$ reflection increases rapidly, which is accompanied by a reduction in the peak width. Clearly, these behaviors signal the development of the ZB-phase GaNWs below $260 \mathrm{~K}$.

It is known that the reduction in the peak width with decreasing temperature indicates the growth of the crystalline domain. The observed peak profiles for the ZB-phase are much broader then the instrument resolution function show that the crystalline domains are finite sized, which can be described by the finite lattice model [28]. It follows the instrumental resolution function, which can be well approximated by a Gaussian function. We propose that the intensity of the Bragg reflection from finite size systems can be described [29] as 


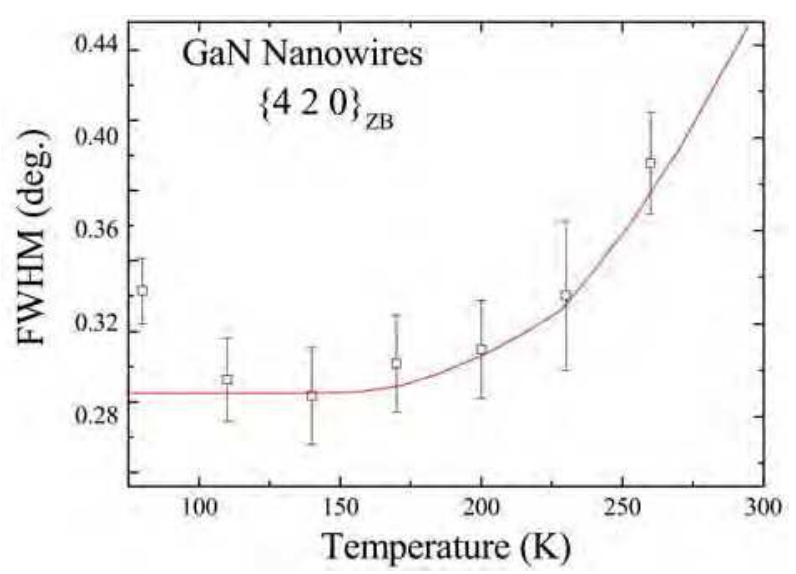

Fig. 12. Temperature dependence of the FWHM of the $\{420\}_{Z B}$ reflection, where the solid curves is guide to the eye only. The temperature dependency of the FWHM of the selected peak of $\{420\}_{Z \mathrm{~B}}$ indicates the structure of the ordering parameter with temperature.

$$
I_{h k l}(\theta)=C\left(\frac{1}{v^{2}}\right)\left[\left|F_{h k l}\right|^{2} p\left(\frac{1+\cos ^{2} 2 \theta}{\sin \theta}\right)\right] \frac{e^{-2 M}}{2 \mu} S(\theta)
$$

where $2 \theta$ is the scattering angle, $C$ is the instrumental constant, $e^{-2 M}$ is the Debye temperature factor, $\mu$ is the linear absorption coefficient, $M$ is the multiplicity of the $\{h k l\}$ reflection, $F_{h k l}$ is the structure factor, and the phase factor $S(\theta)$ reads

$$
S(\theta)=\frac{1}{2 \pi} \int_{0}^{\frac{\pi}{2}} \int_{0}^{\pi} \exp \left\{\frac{-8 \pi^{2}}{\lambda^{2}} \zeta^{2}\left[\sin \theta(\sin \alpha \cos \beta+\sin \alpha \sin \beta+\cos \alpha)-\sin \theta_{B}\right]^{2}\right\} d \alpha d \beta .
$$

Here $\lambda$ is the wavelength of the incident $\mathrm{x}$-ray, $\theta_{\mathrm{B}}$ is the Bragg angle of the $\{h k l\}$ reflection, and $\xi$ is the correlation length of the Bragg scattering that indicates the characteristic size of the crystalline domains. In Fig. 13 we show the development of the $\{420\}_{Z \text { B }}$ reflection with temperature. No significant ZB-phase crystallinity may be identified at above $260 \mathrm{~K}$. At 230 $\mathrm{K}$ a broad peak at the $\{420\}_{Z B}$ position becomes evident, as shown in Fig. 13(f). The diffraction patterns taken at different temperatures show that this peak starts to develop at $\mathrm{T} \sim 260 \mathrm{~K}$, and becomes saturated in intensity at $\mathrm{T}=140 \mathrm{~K}$. The solid curves shown in Figs.13(a)-(f) indicate the fits of the data to the above expression convoluted with the Gaussian instrumental resolutions function. This reflection originates from the development of finite size atomic crystalline domains that belong to the ZB-GaNWs phase. Fig. 13(i) shows a portion of the diffraction pattern taken in a subsequent warm up to $320 \mathrm{~K}$. It shows that the occurrence of phase separation in temperature cycling is reversible.

This critical scattering originates from the short range ordered domains that can be indexed by the ZB-GaNWs, as observed by the in situ x-ray diffraction method. The correlation length $\xi$ of the Bragg scattering that represents the characteristic size of the ordered domain can be used to investigate the growth of the GaNWs. Figure 14 shows the obtained correlation lengths of GaNWs versus temperatures. The results show that the self 
organization process is characterized by a rapid initial growth rate that slows down and self-terminates. This solid curve shown in Fig. 14 describes an exponential growth function [30], namely $\xi=\xi_{o}-\beta e^{\frac{T}{\tau}}$, where $\xi_{\mathrm{o}}=23.8 \mathrm{~nm}, \tau=75.3 \mathrm{~K}$, and $\beta=0.776 \mathrm{~nm}$ represent the initial constants and the fitted parameters, respectively. Furthermore, the nanowire growth rate, defined by $\mathrm{G}=|\mathrm{d} \xi / \mathrm{dT}|$, can be used to probe the growth rate of short range domain. Thus, at $\mathrm{T}=230$ to $80 \mathrm{~K}$, we have a growth rate of $0.0103 \AA / \mathrm{K}$ and a self-terminated length of $\xi_{\mathrm{o}}=23.8 \mathrm{~nm}$.

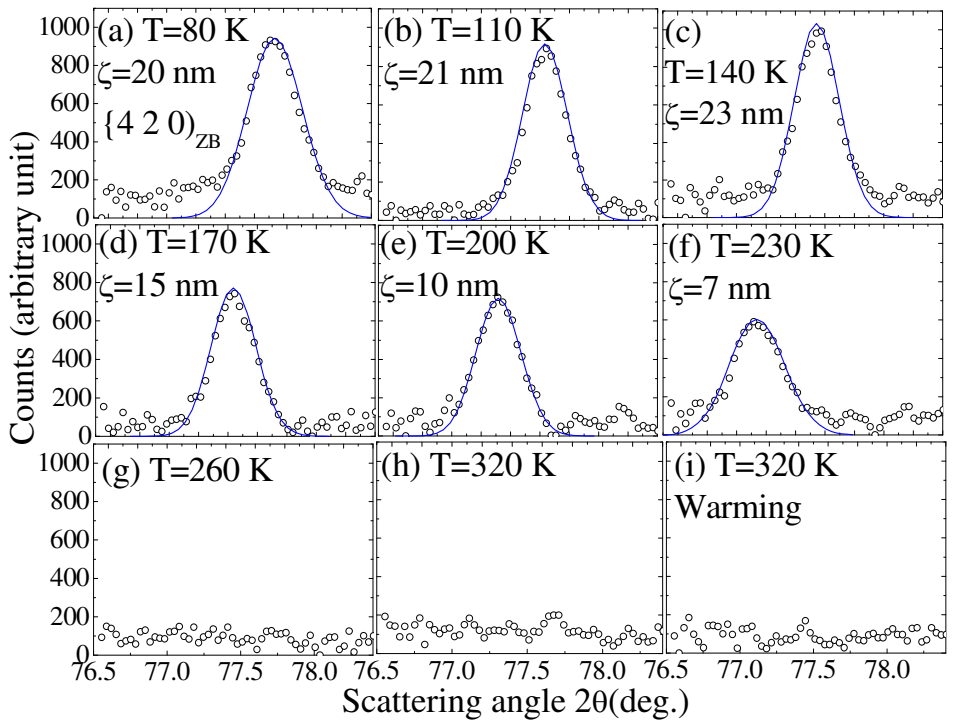

Fig. 13. Variations of the $\{420\}_{\mathrm{ZB}}$ reflection with temperature. The solid curves indicate the fitted of the data to the diffraction profile for finite size structure.

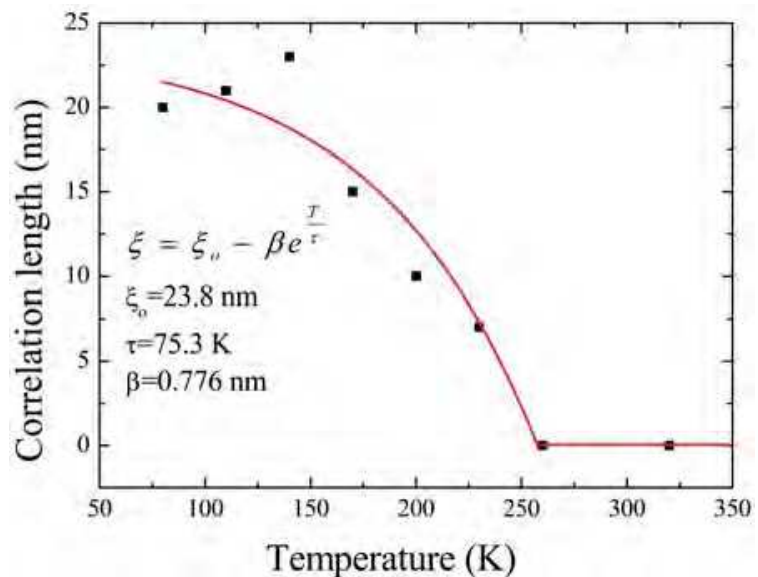

Fig. 14. Temperature dependence of the obtained correlation lengths, revealing a growth rate of $0.0103 \AA / \mathrm{K}$ and self-terminated length if $\xi_{0}=23.8 \mathrm{~nm}$. 


\section{Conclusion}

In conclusion, we have fabricated GaN nanowires employing the LPTCVD method, which we take the advantage of the reaction of gallium with $\mathrm{NH}_{3}$. The mean diameter of the $\mathrm{GaN}$ nanowires fabricated was $40(3) \mathrm{nm}$, and their crystallized into the known wurtzite GaN structure at ambient temperatures. Profile refining of the diffraction patterns shows that the low temperature patterns cannot be described using the hexagonal $\alpha-G a N$ solely. The ZB$\mathrm{GaN}$ phase was found to develop below $260 \mathrm{~K}$. A new short range ordered ZB-GaN phase was observed. The width of the diffraction profile associated to ZB-GaN is noticeably larger than that of the WZ-GaN phase. Short range ordering effect and the phase distribution of random $\mathrm{ZB}-\mathrm{GaNWs}$ must be taken into account. A short range modeling was employed to identify the correlation lengths of the temperature dependence to the ordered domains [31]. The short-range ordered domains observed are not only of great interest for understanding the thermal effect of the phase separation in the GaNWs system (e.g., for $\mathrm{CuO}[32,33], \mathrm{WO}_{2}$ [34], $\mathrm{MoO}_{2}[35]$ and $\mathrm{Ta}_{2} \mathrm{O}_{5}$ nanowires [36-41]) but also for investigating fundamental physics and mechanisms in the future.

\section{Acknowledgement}

We would like to thank the National Science Council of the Republic of China for the financial support through project numbers NSC 97-2112-M-259-004-MY3.

\section{References}

[1] Martin, C. R. (1994). Nanomaterials: A Membrane-Based Synthetic Approach. Science, Vol. 266, (December 1994) pp. 1961-1966, ISSN 1095-9203

[2] Duan, X.; Huang, Y.; Cui, Y.; Wang, J. \& Lieber, C. M. (2001). Indium phosphide nanowires as building blocks for nanoscale electronic and optoelectronic devices. Nature,Vol. 409, (January 2001) pp. 66-69, ISSN 0028-0836

[3] Xia, Y.; Yang, P.; Sun, Y.; Wu, Y.; Mayers, B.; Gates, B.; Yin, Y.; Kim, F. \& Yan, H. (March 2003). One-Dimensional Nanostructures: Synthesis, Characterization, and Applications. Advanced Materials,Vol. 15, (March 2003) pp. 353-389, ISSN 1687-4110

[4] Shi, B. M.; Xie, M. H.; Wu, H. S.; Wang, N. \& Tong, S. Y. (2006). Transition between wurtzite and zinc-blende GaN: An effect of deposition condition of molecular-beam epitaxy. Applied Physics Letters, Vol. 89, (October 2006) pp. 151921-1-151921-3, ISSN 0003-6951

[5] Yang, J. W.; Kuznia, J. N.; Chen, Q. C.; Asif Khan, M.; George, T.; De Graef, M. \& Mahajan, S. (1995). Temperature-mediated phase selection during growth of GaN on (111)A and ( $\overline{1} \overline{1} \overline{1})$ B GaAs substrates. Applied Physics Letters, Vol. 67, (December 1995) pp. 3759-3761, ISSN 0003-6951

[6] Kuykendall, T.; Pauzauskie, P. J.; Zhang, Y.; Goldberger, J.; Sirbuly, D.; Denlinger, J.; \& Yang, P. (2004). Crystallographic alignment of high-density gallium nitride nanowire arrays. Nature Materials,Vol. 3, (July 2004) pp. 524-528, ISSN 0003-6951

[7] Cavallini, A.; Polenta, L.; Rossi, M.; Richter, T.; Marso, M.; Meijers, R.; Calarco, R. \& Lüth, H. (2006). Defect Distribution along Single GaN Nanowhiskers. Nano Letters, Vol. 6, (June 2006) pp. 1548-1551, ISSN 1530-6984

[8] Dahara, S.; Datta, A.; Wu, C. T.; Lan, Z. H.; Chen, K. H.; Wang, Y. L.; Hsu, C. W.; Shen, C. H.; Chen, L. C. \& Chen, C. C. (2004). Hexagonal-to-cubic phase transformation in GaN nanowires by Ga+ implantation. Applied Physics Letters, Vol. 84, (June 2004) pp. 5473-5475, ISSN 0003-6951 
[9] McMahon, M. I. \& Nelmes, R. J. (2005). Observation of a Wurtzite Form of Gallium Arsenide. Physical Review Letters, Vol. 95, (November 2005) pp. 215505-215508, ISSN 1063-7850

[10] Rietveld, H. M. (1969). A profile refinement method for nuclear and magnetic structures. Journal of Applied Crystallography,Vol. 2, (June 1969) pp. 65-71, ISSN 1095-9203

[11] Liang, C. H.; Chen, L. C.; Hwang, J. S.; Chen, K. H., Hung, Y. T. \& Chen, Y. F. (2002). Selective-area growth of indium nitride nanowires on gold-patterned $\mathrm{Si}(100)$ substrates. Applied Physics Letters., Vol. 81, (July 2002) pp. 22-24, ISSN 0003-6951

[12] Ponce, F.A.\& Bour, D. P. (1997). Nitride-based semiconductors for blue and green lightemitting devices. Nature, Vol. 95, (March 1997) pp. 351-359, ISSN 0028-0836

[13] Nakamura, S. (1998). The Roles of Structural Imperfections in InGaN-Based Blue LightEmitting Diodes and Laser Diodes. Science, Vol. 281, (August 1998) pp. 956-961, ISSN 1095-9203

[14] Maruska, H. P. \& Tietjent, J. J. (1969). THE PREPARATION AND PROPERTIES OF VAPOR-DEPOSITED SINGLE-CRYSTAL-LINE GaN. Applied Physics Letters, Vol. 281, (November 1969) pp. 327-329, ISSN 0003-6951

[15] Alivisatos, A. P. (1996). Semiconductor Clusters, Nanocrystals, and Quantum Dots. Science, Vol. 271, (February 1996) pp. 933-937, ISSN 1095-9203

[16] Zolpher, J. C.; Shul, R. J.; Baca, A. G.; Wilson, R. G.; Pearton, S. J.; Stall, R. A. (1996). Ionimplanted GaN junction field effect transistor. Applied Physics Letters, Vol. 68, (April 1996) pp. 2273-2275, ISSN 0003-6951

[17] Duan, X. \& Leiber, C. M. (2000). Laser-Assisted Catalytic Growth of Single Crystal GaN Nanowires. Journal of the American Chemical Society, Vol. 68, (December 1999) pp. 188-189, ISSN 0002-7863

[18] Han, W.; Fan, S.; Li, Q. \& Hu, Y. (1997). Synthesis of Gallium Nitride Nanorods Through a Carbon Nanotube-Confined Reaction. Science, Vol. 277, (August 1997) pp. 1287-1289, ISSN 1095-9203

[19] Shi, W. S.; Zheng, Y. F.; Wang, N.; Lee, C. S.; Lee, S. T. (2001). Microstructures of gallium nitride nanowires synthesized by oxide-assisted method. Chemical Physics Letters, Vol. 345, (September 2001) pp. 377-380, ISSN 0009-2614

[20] Li,J.Y.; Chen,X. L.; Qiao, Z. Y.; Cao,Y. G.; Lan, Y. C. (2000). Formation of GaN nanorods by a sublimation method. Journal of Crystal Growth, Vol. 213, (June 2000) pp. 408410, ISSN 0022-0248

[21] Chen, C. C.; Yeh, C. C.; Chen, C. H.; Yu, M. Y.; Liu, H. L.; Wu, J. J.; Chen, K. H.; Chen, L. C.; Peng, J. Y.; Chen, Y. F. (2001). Catalytic Growth and Characterization of Gallium Nitride Nanowires. Journal of the American Chemical Society, Vol. 123, (February 2001) pp. 2791-2798, ISSN 0002-7863

[22] Chang, K. W.; Wu, J. J. (2002). Low-Temperature Catalytic Synthesis of Gallium Nitride Nanowires. Journal of Physical Chemistry B, Vol. 106, (July 2002) pp. 7796-7799, ISSN 1520-5207

[23] Lyu, S. C.; Cha, O. H.; Suh, E. K.; Ruh, H.; Lee, H. J.; Lee, C. J. (2002). Catalytic synthesis and photoluminescence of gallium nitride nanowires. Chemical Physics Letters, Vol. 367, (January 2003) pp. 136-140, ISSN 0009-2614

[24] Pearton, S. J. (1997). GaN and Related Materials, CRC Press, ISSN 978-9056995171, Amsterdam

[25] Larson, A. C. \& Von Dreele, R. B. (1990). General Structure Analysis System, Report LAUR-86-748, Los Alamos National Laboratory, Los Alamos, NM.

[26] Muñoz, A. \& Kunc, K. (1991). High-pressure phase of gallium nitride. Physical Review B, Vol. 44, (July 1991) pp. 10372 - 10373, ISSN 1098-0121 
[27] Yeh, C. Y.; Lu, Z. W.; Froyen, S. \& Zunger, A. (1992). Zinc-blende-wurtzite polytypism in semiconductors. Physical Review B, Vol. 46, (July 1992) pp. 10086 - 10097, ISSN 1098-0121

[28] Li, W. -H.; Hsieh, W. T. \& Lee, K. C. (1995). Dependence of powder neutron scattering on the dimensionality of magnetic order. Journal of Physics : Condensed Matter, Vol. 7, (August 1995) pp. 6513-6522, ISSN 0953-8984

[29] Wu, S. Y.; Li, W. -H.; Lee, K. C.; Lynn, J. W.; Meen, T. H. \& Yang, H. D. (1996). Twoand three-dimensional magnetic correlations of $\mathrm{Tb}$ in $\mathrm{Pb} 2 \mathrm{Sr} 2 \mathrm{TbCu} 3 \mathrm{O} 8$. Physical Review B ,Vol. 54, (June 1995) pp. 10019 - 10026, ISSN 1098-0121

[30] Lu, Y. S., Wu, H. I., Wu, S. Y., Ma, Y. -R. (2007) Tip-induced large-area oxide bumps and composition stoichometry test via atomic force microscopy. Surface Science,.Vol. 601, (October 2007) pp.3788-3791, ISSN 0039-6028

[31] Wu, S. Y., Ji, J. -Y., Chou, M. H., Li, W. -H. \& Chi, G. C. Low-temperature phase separation in GaN nanowires: An in situ x-ray onvestigation. Applied Physics Letters, Vol. 92, (April 2008) p. 161901, ISSN 0003-6951

[32] Zheng, X. G, Kubozono, H., Yamada, H., Kato, K., Ishiwata Y. \& Xu, C. N. Giant negative thermal expansion in magnetic nanocrystals. Nature Nanotechnology, Vol. 3, (October 2008) pp.724-726, ISSN 1748-3387

[33] Cheng, C. -L., Ma, Y. -R., Chou, M. H., Huang, C. Y., Yeh, V. \& Wu, S. Y. Direct observation of short-circuit diffusion during the formation of a single cupric oxide nanowire, Nanotechnology, Vol. 18, (May 2007) p. 265604, ISSN 0957-4484

[34] Lu, D. Y.; Chen, J.; Chen, H. J.; Gong, L.; Deng, S. Z.; Xu, N. S. \& Liu, Y. L. (2007). Raman study of thermochromic phase transition in tungsten trioxide nanowires. Applied Physics Letters, Vol. 90, (January 2007) p. 041919, ISSN 0003-6951

[35] Kumari, L.; Ma, Y. -R.; Tsai, C. C.; Lin, Y. W.; Wu, S. Y.; Cheng, K. W. \& Liou, Y. (2007). $\mathrm{X}$-ray diffraction and Raman scattering studies on large-area array and nanobranched structure of $1 \mathrm{D} \mathrm{MoO}_{2}$ nanorods. Nanotechnology,Vol. 18, (March 2007) pp. 115717-115723, ISSN 0957-4484

[36] Deavn R. S., Ho, W. -D., Lin, J. -H., Wu, S. Y., Ma, Y. -R.; Lee \& Liou, Y. (2008). X-ray diffraction study of a large-scale and high-density array of one-dimensional crystalline Tantaium Oentoxide nanorods. Grystal Growth \& Design,Vol. 8, (October 2008) pp. 4465-4468, ISSN 1528-7483

[37] Wu, S.; Chan, H. M. \& Harmer, M. P. (2005) Effect of Alumina Additions on Microstructural Aspects of the $\beta$ to a Transformation in Tantalum (V) Oxide. Journal of the American Ceramic Society,Vol. 88, (June 2005) pp. 2369-2373. ISSN 0002-7820

[38] Hale, J. S.; DeVries, M.; Dworak, B. \& Woollam, J. A. (1998) Visible and infrared optical constants of electrochromic materials for emissivity modulation applications. Thin Solid Films, Vol. 313-314, (February 1998) pp.205-209 ISSN 0040-6090

[39] Yoshimura, H.\& Koshida, N. (2006) Thermally crosslinked hole-transporting layers for cascade hole-injection and effective electron-blocking/exciton-confinement in phosphorescent polymer light-emitting diodes. Applied Physics Letters, Vol. 88, (Feburary 2005) p. 093509, ISSN 0003-6951

[40] González, J.; Ruiz, M. D. C.; Rivarola, J. B.; Pasquevich, D. (1998) Effects of heating in air and chlorine atmosphere on the crystalline structure of pure Ta2O5 or mixed with carbon. Journal of Material Science,. Vol. 33, (August 1998) pp.4173. -4180, ISSN 0022-2461

[41] Kukli, K.; Ritala, M.; Matero R. \& Leskela, M. (2000) Influence of atomic layer deposition parameters on the phase content of $\mathrm{Ta}_{2} \mathrm{O}_{5}$ films. Journal of Crysta. Growth, Vol 212, (May 2000) pp.459-568, ISSN 0022-0248 


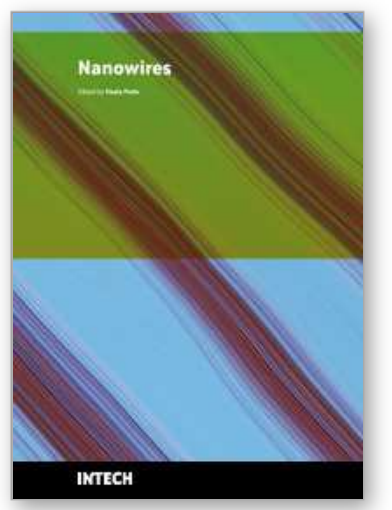

\author{
Nanowires \\ Edited by Paola Prete
}

ISBN 978-953-7619-79-4

Hard cover, 414 pages

Publisher InTech

Published online 01, February, 2010

Published in print edition February, 2010

This volume is intended to orient the reader in the fast developing field of semiconductor nanowires, by providing a series of self-contained monographs focusing on various nanowire-related topics. Each monograph serves as a short review of previous results in the literature and description of methods used in the field, as well as a summary of the authors recent achievements on the subject. Each report provides a brief sketch of the historical background behind, the physical and/or chemical principles underlying a specific nanowire fabrication/characterization technique, or the experimental/theoretical methods used to study a given nanowire property or device. Despite the diverse topics covered, the volume does appear as a unit. The writing is generally clear and precise, and the numerous illustrations provide an easier understanding of the phenomena described. The volume contains 20 Chapters covering altogether many (although not all) semiconductors of technological interest, starting with the IV-IV group compounds ( $\mathrm{SiC}$ and SiGe), carrying on with the binary and ternary compounds of the III-V (GaAs, AIGaAs, GaSb, InAs, GaP, InP, and GaN) and II-VI ( $\mathrm{HgTe}, \mathrm{HgCdTe}$ ) families, the metal oxides ( $\mathrm{CuO}, \mathrm{ZnO}, \mathrm{ZnCoO}$, tungsten oxide, and $\mathrm{PbTiO}$ ), and finishing with $\mathrm{Bi}$ (a semimetal).

\title{
How to reference
}

In order to correctly reference this scholarly work, feel free to copy and paste the following:

Sheng Yun Wu (2010). Low Temperature Phase Separation in Nanowires, Nanowires, Paola Prete (Ed.), ISBN: 978-953-7619-79-4, InTech, Available from: http://www.intechopen.com/books/nanowires/lowtemperature-phase-separation-in-nanowires

\section{INTECH}

open science | open minds

\section{InTech Europe}

University Campus STeP Ri

Slavka Krautzeka 83/A

51000 Rijeka, Croatia

Phone: +385 (51) 770447

Fax: +385 (51) 686166

www.intechopen.com

\section{InTech China}

Unit 405, Office Block, Hotel Equatorial Shanghai

No.65, Yan An Road (West), Shanghai, 200040, China 中国上海市延安西路65号上海国际贵都大饭店办公楼405单元

Phone: +86-21-62489820

Fax: $+86-21-62489821$ 
(C) 2010 The Author(s). Licensee IntechOpen. This chapter is distributed under the terms of the Creative Commons Attribution-NonCommercialShareAlike-3.0 License, which permits use, distribution and reproduction for non-commercial purposes, provided the original is properly cited and derivative works building on this content are distributed under the same license. 